\title{
CONTRIBUIÇÕES PARA A EDUCAÇÃO CIENTÍFICA NA REGIÃO DE RIBEIRÃO PRETO/SP
}

\author{
CONTRIBUTIONS TO SCIENTIFIC EDUCATION IN THE REGION OF \\ RIBEIRÃO PRETO/SP
}

*Daniela Gonçalves de Abreu, **Thiago de Souza Cavallini, ***João Ricardo Sanchez, ****Daniela Mica Espimpolo

\section{RESUMO}

Este projeto foi criado pelo Centro de Ensino Integrado de Química (CEIQ) do Departamento de Química da Faculdade de Filosofia, Ciências e Letras de Ribeirão Preto visando contribuir para a educação científica, principalmente de jovens em idade escolar na Região de Ribeirão Preto. Ele tem possibilitado a promoção de vários eventos, tais como: Olimpíadas de Química; realização de visitas de escolas à Universidade; oferecimento de oficinas para estudantes e professores de ensino médio. Em todas as atividades são discutidos conceitos formativos e informativos com os participantes. Os licenciandos em química, que atuam como monitores, têm oportunidade de colaborar na organização e realização das atividades, podendo ampliar sua formação. Este projeto abre precedentes para uma divulgação contínua da ciência, importante para a formação de cidadãos. As atividades, além de beneficiar os alunos do Ensino Médio que puderam conhecer um pouco da Universidade e discutir a Química como ciência e profissão, também se constituíram em um espaço para a formação inicial do professor de química.

Palavras-chave: Química. Ensino Médio. Divulgação científica.

\section{ABSTRACT}

This project was created by the Center of Chemistry Integrated Teaching of the Department of Chemistry of Faculdade de Filosofia, Giências e Letras de Ribeirão Preto to contribute to science education, especially of teens in the region of Ribeirão Preto. This Center enables the promotion of various events like the Olympiad of Chemistry, school visits to the University, offering workshops for high school students and teachers. In all activities, information and formative concepts are discussed with participants. The students of chemistry who act as monitors have the opportunity to collaborate in organization and in implementation of activities and may broaden their education. This project promotes continuous dissemination of science, which we think is important for the formation of citizens. The activities, not only benefit the High School students who could learn about the University and Chemistry as a science and profession, but also provided a space for the initial training of teachers.

Key words: Chemistry. High School. Science education.

\footnotetext{
* Professora da área de Ensino de Química e atual coordenadora do Centro de Ensino Integrado de Química (CEIQ) da Universidade de São Paulo (Ribeirão Preto) - e-mail: danielaga@ffclrp.usp.br. ** Técnico em Química atuante no CEIQ. *** Ex-estagiário e atual professor colaborador do CEIQ. ***** Aluna de Pós-Graduação e colaboradora do GEIQ.
} 


\section{INTRODUÇÃO}

As ciências exatas são, normalmente, pouco prestigiadas pelos estudantes do Ensino Médio que concebem o pensamento científico como sendo de ordem teórica, abstrata e difícil. Além disso, a sociedade em geral concebe estas ciências, em particular a química, de forma desvinculada de um contexto social, ou ainda, associam-na a fatores negativos como, por exemplo, a degradação da natureza, problemas de contaminação do homem por produtos tóxicos e desastres ecológicos que são noticiados pela mídia.

Pode-se dizer que a distância entre o saber abrangido pela escola e aquele gerado e acumulado pelo homem tem crescido assustadoramente. A educação em ciências não se restringe somente à sala de aula no âmbito da escola. Segundo Barba [1], os centros de ciências são locais capazes de possibilitar a apreciação e o entendimento das ciências por meio de ações voluntárias e individuais, popularizando, desta forma, o conhecimento científico e tecnológico.

Os Parâmetros Curriculares Nacionais ( $\mathrm{PGNs}$ ) escolheram a cidadania como eixo principal da educação escolar e assumem que isso implica tratar de valores. Segundo os PGNs, a escola não muda a sociedade, mas pode - partilhando esse projeto com segmentos sociais que assumem os princípios democráticos, articulando-se a eles - constituir-se não apenas como espaço de reprodução, mas também como espaço de transformação [2].

Ainda, para Chassot, “(...) a cidadania só pode ser exercida plenamente se o cidadão tiver acesso ao conhecimento (e isto não significa apenas informações) (...)” [3]. Para Santos e Schnetzler [6], considerando-se que a cidadania se refere à participação dos indivíduos na sociedade, para efetivar a participação comunitária é importante que ele disponha de informações vinculadas aos problemas sociais, os quais demandam um posicionamento quanto ao encaminhamento das soluções.

É de extrema importância que os indivíduos percebam-se como cidadãos ativos, capazes de interferir (positivamente) na realidade que os cercam. É a concientização que permite ao indivíduo um reconhecimento de si mesmo, de sua condição de agente ativo, o que o leva a tornar-se automaticamente crítico, tendo em vista o reconhecimento de sua realidade. Isso fica evidenciado através do depoimento de um homem, ex-operário, participante de um dos cursos realizados por Freire, transcrito em sua obra Pedagogia do Oprimido citado a seguir:

Talvez seja eu, entre os senhores, o único de origem operária. Não posso dizer que haja entendido todas as palavras que foram ditas aqui, mas uma coisa posso afirmar: cheguei a esse curso ingênuo e, ao descobrir-me ingênuo, comecei a tornar-me crítico [5].

Para tanto, há a necessidade de instrumentalizar o indivíduo, após sua conscientização, oferecendo as condições para que atue por si mesmo. Santos propõe "que se instrumentalize o cidadão, que ele ganhe por meio da educação as condições de atuar por si mesmo" [6].

As atividades de extensão universitária podem contribuir para a "instrumentalização do indivíduo", ao passo que podem propiciar transformações na sociedade a partir do despertar da consciência dos indivíduos para a sua condição de cidadãos reflexivos/agentes sobre a sua realidade e por propiciar que estes sejam munidos do conhecimento necessário para efetivar mudanças significativas na mesma (instrumentalização).

Partindo desse pressuposto, o Centro de Ensino Integrado de Química (CEIQ) do Departamento de Química da Faculdade de Filosofia, Giências e Letras de Ribeirão Preto (DQ-FFCLRP-USP) tem desenvolvido atividades de extensão visando contribuir para a educação científica, principalmente, de jovens em idade escolar na Região de Ribeirão Preto.

O CEIQ foi criado em I99I, numa época em que a procura pelo Curso de Química na instituição era significativamente baixa. É um centro bastante procurado por estudantes e professores da Região de Ribeirão Preto por realizar Olimpíadas Regionais de Química (ORQs); organizar visitas monitoradas ao Departamento de Química; desenvolver experimentos de ciências e outros materiais para as escolas de Ensino Fundamental da cidade; oferecer oficinas sobre temas ambientais; organizar exposições e oficinas; e por produzir materiais didáticos. O CEIQ desempenha um papel importante no que diz respeito ao incentivo de posturas mais críticas da sociedade através das mais diversas formas de produção de conhecimento e divulgação da ciência.

As atividades de extensão desenvolvidas pelo GEIQ objetivam principalmente: 
a) despertar e estimular o interesse dos alunos pelas ciências, em especial, pela Química;

b) incentivar e aprofundar o debate na comunidade escolar sobre temas de importância social, propiciando a contextualização dos conteúdos das disciplinas científicas;

c) apresentar aspectos mais realistas da profissão do químico e a sua importância dentro do atual contexto social;

d) valorizar a mobilização de professores e alunos no ambiente escolar;

e) proporcionar desafios aos estudantes relacionados ao saber científico;

f) aproximar a Universidade das escolas de educação básica;

g) identificar os estudantes que possuem habilidades e interesse pela Giência estimulando-os a seguir carreiras em áreas científico-tecnológicas;

h) contribuir para formação de indivíduos conscientes de seu papel na sociedade.

Dessa forma, nos deteremos neste artigo a relatar e discutir as atividades de extensão desenvolvidas pelo CEIQ, nos três últimos anos, dentro do projeto "Contribuições para a educação científica na Região de Ribeirão Preto", apoiado pela Pró-Reitoria de Cultura e Extensão Universitária da USP.

\section{MATERIAIS E MÉTODOS}

\section{OLIMPÍADAS REGIONAIS DE QUÍMICA}

As ORQ têm sido realizadas em duas fases, sendo que na primeira fase (primeiro semestre do ano) o professor de Química da escola, muitas vezes em parceria com professores de outras disciplinas como Português, Giências e História, seleciona, com os critérios que julgar pertinentes, aproximadamente quarenta alunos para visitar o Departamento de Química. Essas visitas incluem palestras sobre o tema ORQ e experimentos demonstrativos, bem como a apresentação do laboratório didático.

$\mathrm{Na}$ etapa seguinte (segundo semestre do ano), o professor da escola seleciona seis alunos (dois de cada série do Ensino Médio), de acordo com os seus critérios, para compor a equipe representante da escola. A segunda fase é realizada no Departamento de Química e inclui a resolução de situações-problema por meio da experimentação e de exercícios teóricos. Nesta fase, os alunos resolvem as provas sempre em equipe e pretende-se com isso que aprendam a colocar o seu conhecimento à disposição dos outros e a trabalhar de forma colaborativa por um objetivo comum. Enquanto os alunos realizam as provas, são oferecidas oficinas para os professores de Ensino Médio que os acompanham. A equipe vencedora, além de receber prêmios como medalhas e troféus, também é convidada a fazer um estágio de 40 horas em laboratórios de pesquisa do Departamento de Química.

Foram desenvolvidos os seguintes temas até o momento: "A Química, os combustíveis e o meio ambiente" (2003); "Química e Saúde: tratamento e prevenção de doenças" (2004); "A química na busca da justiça e paz social" (2005); "Química, estética e saúde" (2006); "Química e a vida na Terra: como eu cuido e como eu degrado..." (2007); "Química e Energia: movendo a Humanidade" (2008) e "Química, agricultura e desenvolvimento: cultive esta ideia" (2009). Neste ano (2010), o tema que está sendo abordado é "A Química através dos tempos: viaje nesta história...”.

\section{ORGANIZAÇÃO DE VISITAS AO DEPARTAMENTO DE QUÍMICA}

Primeiramente, as escolas agendaram por telefone uma visita com aproximadamente quarenta alunos ao Departamento de Química. Algumas vezes, nesta ocasião, combinou-se com o professor da escola as atividades das quais os alunos participariam na universidade. Antes da visita, experimentos foram organizados e otimizados, roteiros de atividades práticas com materiais simples e de baixo custo foram elaborados, bem como material informativo e introdutório das atividades no DQ. Uma palestra foi planejada e oficinas foram oferecidas para os alunos de Licenciatura em Química com interesse em colaborar na realização das atividades.

\section{REALIZAÇÃO DE EXPERIMENTOS EM ESCOLAS}

Desde 2003, o GEIQ tem parceria com a Casa da Giência Galileu Galilei (CGGG) da Secretaria Municipal de Educação de Ribeirão Preto. A referida instituição comprou um ônibus e o adaptou para que experimentos das Ciências da Natureza pudessem ser realizados em seu interior. Dessa forma, devido à parceria, os alunos do Ensino Médio podem ter um contato maior com a Química já que o ônibus assemelha-se 
a um "laboratório itinerante". As atividades desenvolvidas no ônibus foram planejadas e discutidas com a equipe da CGGG. Foi necessário realizar uma adequação da linguagem para os alunos do Ensino Fundamental e, ainda, procurou-se contextos que permitissem abordar a química de forma vinculada a aspectos sociais, culturais, históricos.

\section{ORGANIZAÇÃO DE UMA EXPOSIÇÃO TEMÁTICA} CIENTÍFICA E OFERECIMENTO DE OFICINAS

No segundo semestre de 2008 foi realizada a exposição "A ciência de mãos dadas com o meio ambiente", com o objetivo de gerar discussão sobre formas de obtenção de energia, impactos ambientais e sociais e o papel da química neste processo. A exposição também incluiria discussões sobre a preservação de recursos hídricos na Região de Ribeirão Preto. Para isso, foi necessário realizar a:

a) seleção de imagens associadas com a química na sociedade;

b) organização das imagens em painéis que seriam apresentados aos visitantes;

c) elaboração de questões referentes a imagens, que fizeram parte de um "Quiz interativo", visando fazer com que as pessoas refletissem sobre a imagem/concepção que têm sobre a química;

d) elaboração de um jogo que simulasse o funcionamento de um conversor catalítico de automóveis. Para isto foram utilizados materiais alternativos como restos de madeira, garrafas plásticas, esferas coloridas (usadas para confeccionar bijuterias), isopor e canos plásticos;

e) produção de cartazes numa forma dialógica, já que a intenção era, de certa forma, "interagir" por meio dos textos com os visitantes;

f) confecção de maquetes com papel reciclável, tinta guache, restos de madeira, entre outros;

g) seleção e otimização de experimentos que poderiam ser realizados pelo público visitante, usando materiais de baixo custo, como, por exemplo, garrafas PET e copos de vidro;

h) elaboração de textos autoexplicativos e interativos para acompanhar as maquetes.

A exposição esteve aberta ao público durante os meses de novembro e dezembro de 2008. Todos os materiais produzidos para a exposição foram incluídos posteriormente no planejamento de duas oficinas de 2 horas de duração cada: uma delas foi intitulada "Contribuições da Química na Educação Ambiental para preservação dos recursos hídricos" e a outra "Química verde e contribuições para a educação científica na escola básica". Apostilas, contendo os assuntos abordados durante as oficinas, foram elaboradas e disponibilizadas para alunos e professores da escola básica, que frequentaram as oficinas, cujo oferecimento se deu na Casa da Ciência Galileu Galilei.

\section{RESULTADOS E DISCUSSÃO}

\section{OLIMPIAADAS REGIONAIS DE QUÍMICA}

Como dito anteriormente, o tema abordado na VII Olimpíadas Regionais de Química (ORQ) foi "Química, agricultura e desenvolvimento: cultive esta ideia". A palestra desta ORQ foi elaborada considerando-se tema, estrutura e imagem. O objetivo da palestra era discutir com os visitantes as relações entre a química, a agricultura e o desenvolvimento, mas de forma imparcial. Não se pretendia abordar apenas os aspectos negativos relacionados ao uso de agrotóxicos, ou ainda, apenas os aspectos positivos relacionados aos melhoramentos.

O tema foi tratado sob o ponto de vista de diferentes áreas do conhecimento, como Química, História, Biologia, Geografia e Português. Abordou-se, por exemplo, a definição da palavra agricultura; a utilização do solo ao longo da história; o crescimento de plantas; tipos de solos; polinização; fotossíntese; cadeia alimentar; controle de pragas; adubos e fertilizantes; utilização da água na agricultura, dentre outros.

Houve uma preocupação em dialogar com os estudantes e valorizar seus conhecimentos prévios sobre o assunto. Durante toda a apresentação foram feitas questões, como por exemplo: "O que é agricultura?", "As plantas precisam de cuidados para crescer? Quais?", "Como os insetos poderiam afetar uma plantação? E os fungos e bactérias?”. Em algumas situações os estudantes foram desafiados a pensar como agricultores, que deveriam considerar as implicações envolvidas num determinado cultivo, como, por exemplo, possível improdutividade do solo e alteração nos recursos hídricos regionais.

Nos slides, foram criados links para que alguns itens ("Pesticidas", "Agroecologia", "Controle Biológico", entre outros) fossem aprofundados. Informações 
sobre agricultura orgânica, alterações genéticas, hidroponia, entre outros, fizeram parte da palestra.

Depois da visita, o tema da ORQ deveria ser trabalhado nas escolas e os estudantes produziriam redações a partir daí que os ajudaria a se preparar para a segunda fase, composta por provas teóricas e experimentais.

A palestra foi apresentada a 36 escolas (cerca de I440 alunos) inscritas na primeira fase da VII ORQ. Destas 12 eram de Ribeirão e 24 eram da região. É possível perceber a consolidação do evento pelo número de escolas. Professores de diferentes áreas (história, português, biologia entre outras) têm acompanhado os alunos durante as fases da olimpíada. Na cerimônia de premiação (ocorrida em novembro de 2008) estiveram presentes aproximadamente cem pessoas, sendo alunos de Ensino Médio, professores e familiares.

Durante a VII ORQ (2008) foram coletados depoimentos de professores durante a segunda fase e posteriormente disponibilizados. Veja alguns depoimentos:

"A olimpíada é uma oportunidade dos alunos da escola pública de conhecer a universidade..." Professora X

"A interação entre a universidade e a escola pública é importante pois mostra aos alunos como é a universidade e que ele pode fazer parte dela. Serve também como um incentivo..." Professor T

"A meu ver, é importante, pois incentiva o aluno a estudar e aproxima a escola pública e a universidade. Socialmente é uma atividade diferente do ambiente escolar..." Professora D

Também vale destacar que em 2008 foi realizada uma investigação visando conhecer qual a influência das Olimpíadas de Química nas escolas. Para isso, durante a segunda fase da VII ORQ foi realizada uma oficina com os professores e nesta ocasião discutiu-se o tema com os mesmos. A pesquisa fez parte de uma monografia entregue num Curso de Especialização em Ensino de Ciências promovido pela Secretaria Municipal de Educação e Faculdade de Filosofia, Giências e Letras de Ribeirão Preto. A investigação sobre o impacto das ORQ nas escolas também foi objeto de estudo da monografia de um aluno da Licenciatura em Química no ano de 2009, os sujeitos envolvidos e entrevistados foram os alunos de Ensino Médio participantes.
Neste ano, a VIII Olimpíada Regional de Química com o tema "A Química através dos tempos: viaje nesta história..." pretendeu abordar a construção da ciência química e suas diversas aplicações. Na palestra da primeira fase foi abordada a construção do conhecimento químico ao longo da história e sua influência na vida do homem. No início da palestra discutiu-se como o homem primitivo conquistou o domínio do fogo e de que forma esta conquista contribuiu para novos hábitos, por exemplo, a organização social que, consequentemente, estimulou o desenvolvimento da linguagem; o cozimento das carnes como forma de higienizá-la contra microorganismos indesejados e proporcionar uma alimentação mais saudável e saborosa.

Assuntos como metalurgia, tinturaria e vidros foram retratados da antiguidade até os dias atuais. Por exemplo, o homem da antiguidade fabricava suas tintas utilizando tanto pigmentos inorgânicos extraídos de minerais quanto orgânicos extraídos das plantas que, misturados com clara de ovo, dava origem às tintas.

Os fenômenos químicos sempre existiram, no entanto, a denominação de "Giência Química" aconteceu só no século XVII. Todo o período da alquimia até o século XVII, com os experimentos de Lavoisier, foi abordado procurando-se destacar a não linearidade na construção da ciência.

No final da palestra, destacou-se o tema "Polímeros", utilizados nos mais variados setores. Por exemplo, na área da saúde, a substituição de seringas de vidro por seringas de plásticos descartáveis possibilitou diminuir o risco de contaminação. Porém, a utilização excessiva de plásticos gera um volume considerável de lixo. Neste momento, abordamos a importância da coleta seletiva, reciclagem e apresentamos o projeto "USP Recicla”.

\section{ORGANIZAÇÃO DE VISITAS AO DEPARTAMENTO DE QUIMICA}

Ao longo de 2008, dez escolas de Ensino Médio realizaram visitas ao $\mathrm{DQ}$ (cerca de 380 alunos). Os estudantes participaram de uma palestra sobre os cursos oferecidos pelo DQ e sobre a atuação do químico no mercado de trabalho. Procurou-se selecionar informações sobre os cursos e atuação dos profissionais dos Cursos oferecidos no DQ:

a) Bacharelado com Habilitação em Química Tecnológica, Biotecnologia e Agroindústria; 
b) Bacharelado em Química;

c) Bacharelado em Química Forense;

d) Bacharelado com Habilitação em Química Tecnológica;

e) Licenciatura em Química.

Nas palestras procurou-se explorar relações entre ciência, tecnologia e sociedade. Durante as visitas, algumas vidrarias e aparelhos mais comuns foram apresentados aos visitantes. Entre os experimentos apresentados destacam-se:

a) identificação de ferro em alimentos, como no leite, por exemplo;

b) medida da acidez de vários produtos de uso doméstico, como sabão, refrigerante, entre outros;

c) realização de cromatografia em papel e em coluna e das aplicações da Cromatografia em testes de antidopping nos esportistas;

d) mudança de cor de uma solução contendo azul de bromotimol, a partir do sopro e discussão da eliminação de gás carbônico no processo de respiração;

e) etapas envolvidas no tratamento de água e, em particular, houve uma discussão acerca do tratamento de água realizado na cidade de Ribeirão Preto;

f) extração do óleo de cravo por destilação por arraste a vapor;

g) revelação de impressão digital usando iodo.

Durante as visitas ao DQ algumas dúvidas têm se mostrado bastante frequentes, por exemplo, alguns visitantes não sabem que a USP é uma Universidade pública (sem mensalidade a ser paga); querem saber como fazer para se tornar estudante desta Universidade; quantas horas devem estudar diariamente; quais matérias fazem parte dos cursos, entre outras coisas. Os estudantes perguntam se é muito difícil entrar na USP e observa-se a desmotivação em relação a cursar uma Universidade. Desta forma, durante a palestra procura-se trabalhar a motivação do visitante.

\section{REALIZAÇÃO DE EXPERIMENTOS EM ESCOLAS}

Em relação às atividades no ônibus, este chegava à escola no início da semana, alojava-se no estacionamento ou na entrada principal e ali permanecia durante toda a semana até receber todas as turmas do Ensino Fundamental. Os alunos eram divididos em turmas de dez alunos que se alternaram entre o ôni- bus e a sala de aula. As atividades se iniciavam com uma rápida contextualização da química na vida diária destes alunos, seguida de uma discussão, tentando resgatar o conhecimento prévio dos mesmos. Perguntas como estas eram efetuadas: "Você sabe o que é Química? O que já ouviu falar sobre? Como você acha que a química está presente em seu dia a dia? Seria possível viver sem a química? Cite exemplos de onde há Química em seu cotidiano".

Em seguida, eram feitos experimentos, como por exemplo, a revelação de impressão digital, a cromatografia em papel e as reações ácido/base foram demonstrados. Pode-se perceber pelos diálogos que, mesmo sem cursarem a disciplina de química, os alunos de $5^{\mathrm{a}}$ a $8^{\mathrm{a}}$ série já usam termos específicos relacionados à química em razão de sua vivência. Veja:

"A minha mãe é cabeleireira e usa amônia no salão...” Aluna A

"Já fiz adubo com meu pai, usando fosfato..." Aluno B

“Minha avó faz sabão de 'soda' para lavar a roupa..." Aluno $\mathrm{C}$

Assim, no segundo semestre de 2008, cerca de 2000 alunos de cinco escolas municipais de Ribeirão Preto foram atendidos por este projeto. No primeiro semestre de 2009, outras escolas da região periférica da cidade foram visitadas, e incluíram-se os experimentos "separação de misturas a partir de um funil de separação" e "análise da qualidade do leite".

Este projeto tem possibilitado despertar e estimular o interesse dos alunos do Ensino Fundamental pelas ciências, em especial pela química, a partir de discussões de situações do cotidiano do aluno, situações empíricas, entre outras, favorecendo a construção de uma imagem mais ampla da química, bem como sua contextualização dentro do universo científico, tecnológico e social.

\section{ORGANIZAÇÃO DE UMA EXPOSIÇÃO TEMÁTICA CIENTÍFICA E OFERECIMENTO DE OFICINAS}

A exposição "A ciência de mãos dadas com o meio ambiente" foi visitada por 2327 pessoas, sendo em sua maioria alunos de Ensino Fundamental e Médio.

Para possibilitar reflexões relativas aos recursos hídricos, foram elaborados os seguintes materiais: 
a) uma maquete representando um bairro situado numa zona de recarga do Aquífero Guarani. Na maquete foi ilustrado o processo de obtenção da água que abastecia as casas, a partir da zona saturada do Aquífero. Na maquete podia-se perceber que o Aquífero não se trata de "um rio subterrâneo" e que a água fica retida nos poros e espaços entre as rochas.

b) três garrafas PET foram cortadas ao meio e a parte de cima com a tampa com algumas perfurações, como se fosse um funil, foi encaixada na parte de baixo da garrafa. Colocou-se no fundo deste funil um pouco de algodão e cada um deles foi preenchido, separadamente, com areia, argila e cascalho. Ao lado dos três sistemas, colocou-se uma jarra com água e também um cartaz com informações sugerindo que o visitante adicionasse água em cada um dos funis e observasse. Podia ser observado que, quando colocada na argila, a água demorava mais para ser filtrada; na areia era um pouco mais rápido; no cascalho mais rápido ainda. Posteriormente, apresentamos questões nos cartazes, para que fosse discutida a relação entre o tipo de solo e a recarga da água subterrânea. Quanto menor a porosidade do solo, mais lenta é a recarga.

Uma amostra de rocha porosa, do tipo do aquífero foi conseguida e o visitante era convidado a derramar um pouco de água sobre a mesma. Com isto podia-se perceber que a rocha funcionava como uma "esponja" absorvendo a água derramada.

Para que o visitante pudesse refletir sobre o seu consumo de água, foi disponibilizada em cartaz, uma conta de água de uma família de três membros e também os cálculos e considerações que deveriam ser feitas, para que fosse obtido o consumo individual. A média de consumo de água em Ribeirão Preto foi comparada com a de outros estados e até mesmo com a de diferentes países.

Para abordar a questão dos recursos hídricos do ponto de vista local, ao invés de ilustrar todas as etapas geralmente presentes no tratamento de água perguntou-se para o visitante: "Você sabe como a água que você bebe aqui em Ribeirão é tratada?". A resposta não era colocada no mesmo cartaz, para dar tempo do visitante pensar sobre o assunto. Mais adiante, havia um cartaz dizendo que "Em Ribeirão a água passa somente pela cloração e fluoretação, pois temos uma água de ótima qualidade!”. Muitos visitantes se surpreendiam com essa informação.

Também se pretendia discutir formas de obtenção de energia, impactos ambientais e sociais e o papel da química neste processo. Para que as informações não fossem apenas apresentadas, procurou-se introduzir as informações a partir de algumas questões e curiosidades que possibilitassem a interação com os visitantes. Por exemplo, ao invés de simplesmente definir energia eólica, antes de tal definição, foi perguntado: "Você sabe o que é energia eólica?". Também podemos destacar: "Você sabia que os primeiros moinhos de vento eram usados para a moagem de grãos e para o bombeamento de água na irrigação?”, "E no Brasil, existem usinas eólicas?", "Você sabe de onde vem a energia que faz o seu aparelho de TV funcionar?", "Você sabia que além da usina hidrelétrica que produz energia elétrica a partir de um desnível d' água, existem outras maneiras de se obter energia elétrica?".

A exposição incentivou reflexões acerca das responsabilidades individuais e a formação de sujeitos pró-ativos. Tivemos a preocupação em trabalhar com conhecimentos, atitudes e valores, não apenas através da transmissão de informações, mas fomentando a participação individual em processos coletivos, trabalhando desde a perspectiva local até a global.

Todos os materiais e textos produzidos para a exposição foram utilizados na oficina sobre "Contribuições da Química na Educação Ambiental para preservação dos recursos hídricos”, da qual participaram I95 alunos do Ensino Fundamental de Ribeirão Preto. Procurou-se abordar o assunto do ponto de vista de diferentes áreas do conhecimento: atividades humanas que demandam água; ciclo da água; água doce e água salgada; destilação simples; distribuição geográfica da água; contaminação das águas subterrâneas; tratamento de água; biodegradabilidade; respiração celular; acidente com melaço no Rio Pardo; eutrofização; desperdício, vazamentos; superexploração, contaminação por agrotóxicos, área de afloramento e confinamento do Aquífero Guarani e permeabilidade e porosidade de diferentes rochas.

$\mathrm{Na}$ oficina denominada "Química verde e contribuições para a educação científica na escola básica" foram selecionadas imagens que ilustrassem aplicações da química na sociedade para a elaboração de um "Quiz interativo”. Optou-se por aquelas imagens, como dito anteriormente, que permitissem 
associação com aspectos diversos, como, por exemplo, medicamentos, cosméticos e um rio poluído com peixes mortos. Então, solicitou-se que os estudantes escolhessem, dentre as figuras, apenas duas que melhor representassem seus pensamentos e julgamentos sobre a Química. O objetivo foi resgatar a imagem/concepção destes sobre a Química e seus impactos na sociedade.

O jogo simulando um conversor catalítico de automóvel foi elaborado com materiais alternativos e a representação dos gases gerados na combustão de gasolina foi feita por esferas coloridas, por exemplo: monóxido de carbono (esferas pretas) e monóxido de nitrogênio (esferas roxas). Ao movimentar o sistema, os estudantes percebiam que as esferas coloridas que representavam cada gás emitido (lado esquerdo da Figura I), ao passar pelo conversor (parte preta da Figura I) feito de garrafa PET e placa de isopor, diminuíam em quantidade ou ainda saiam em cores diferentes, representando outros gases, como por exemplo, $\mathrm{CO}_{2}$ (gás carbônico) e $\mathrm{N}_{2}$ (nitrogênio). Os alunos puderam interagir e discutir a emissão de gases que são gerados no motor do carro, e sua conversão em componentes menos tóxicos lançados na atmosfera.

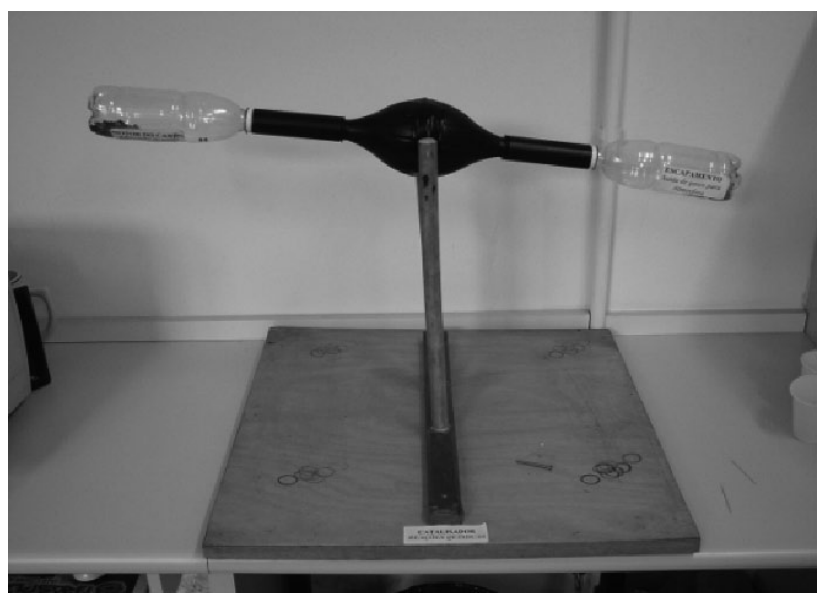

Figura I: Jogo didático simulando um conversor catalítico de automóvel

Uma legenda foi fornecida aos alunos para que cada um pudesse observar quais substâncias eram geradas, convertidas e emitidas durante o processo. Tanto o "Quizinterativo" quanto o jogo didático simulando um conversor catalítico de automóvel fizeram parte da exposição relatada anteriormente. Posteriormente, esses materiais foram incluídos na oficina sobre Química Verde oferecida para alunos de Ensino Médio e também na apostila elaborada para esta finalidade.
A apostila foi escrita utilizando uma linguagem simples e direta, de forma a interagir com o leitor, apresentando a Química Verde e sua importância na redução/eliminação de impactos ambientais gerados em atividades químicas. Abordou-se estequiometria, ocorrência e rendimento de reações químicas e porcentagem de eficiência atômica nessas reações, sempre aliados à proposta ambiental. Durante o primeiro semestre de 2009, I57 alunos de Ensino Médio participaram da oficina.

A oficina possibilitou conhecer um pouco da visão que os alunos têm sobre a química de um modo geral. Acredita-se que os materiais desenvolvidos sejam recursos didáticos que podem contribuir tanto na divulgação da Química Verde, tema recente e ainda desconhecido de muitos alunos, como também em aulas de química no Ensino Médio.

\section{CONCLUSÕES}

As atividades realizadas abrem precedentes para uma divulgação contínua da ciência que julgamos ser importante para a formação de cidadãos. As atividades além de beneficiar os alunos do Ensino Médio que puderam conhecer um pouco da Universidade e discutir a Química como ciência e profissão, também se constituíram em um espaço para a formação inicial do professor de química. As atividades de extensão promovidas pelo CEIQ têm contribuído para a formação dos licenciandos, futuros professores de química, à medida que estes têm a oportunidade de planejar e participar de situações educacionais envolvendo professores e alunos.

Tais atividades possibilitam ao licenciando a vivência de experiências diversas que trazem consigo elementos que são objetos de estudo nas disciplinas, por exemplo, interação professor-aluno, adequação de linguagem de acordo com faixa etária, metodologias de ensino, dentre outras. Desta forma, um desafio que se apresenta é buscar formas de articular as atividades de extensão com disciplinas do Gurso de Licenciatura em Química. 


\section{AGRADECIMENTOS}

Agradecemos a todos os monitores que têm dedicado tempo e esforço para a realização das atividades do GEIQ. Às professoras Joana de Jesus Andrade, Márcia Andréia Mesquita Silva da Veiga, Maria Lúcia de Arruda Moura Gampos e Rogéria Rocha Gonçalves, membros do Centro e Coordenadoras de projetos do Programa Aprender com Cultura e Extensão da USP, os quais se entrelaçam e compõem o projeto discutido neste artigo. À Pró-Reitoria de Cultura e Extensão Universitária da USP pela concessão de apoio financeiro, por meio do Fundo de Cultura e Extensão.

\section{REFERÊNCIAS BIBLIOGRÁFICAS}

[1] BARBA, M. L. P. Os serviços educativos e de popularização de ciência nos museus e centros de ciência e tecnologia: a visão do explorador. Disponível em: http://www.comciencia.br/reportagens/2005/I2/I4. shtml. Acesso em 2I de novembro de 2008.

[2] BRASIL. Ministério da Educação. Secretaria de Educação Média e Tecnológica (Semtec). Parâmetros Curriculares Nacionais para o Ensino Médio. Brasília: MEC/Semtec, 2000.

[3] CHASSOT, A. Alfabetização científica: questões e desafios para a educação. Ijuí: Editora Unijuí, 2003, p. 49.

[4] SANTOS, W. L. P.; Schnetzler, R.P. Educação em química: compromisso com a cidadania. Ijuí: Editora Unijuí, 2000.

[5] FREIRE, P. Pedagogia do Oprimido. ed. 44. Rio de Janeiro: Paz e Terra, 2006.

[6] SANTOS, G. S. dos. Ensino de Giências: Abordagem Histórico-Crítica. Campinas, São Paulo: Armazém do Ipê (Autores Associados), 2005, p. 6. 